Research Article

\title{
Factors Affecting Maintenance Probability and Resurfacing Thickness Based on the Pavement Management System
}

\author{
Hongmei Li, ${ }^{1}$ Jiwang Jiang $\mathbb{D}^{2}{ }^{2}$ and Fujian $\mathrm{Ni}^{2}$ \\ ${ }^{1}$ School of Civil Engineering, Nanjing Institute of Technology, No. 1 Hongjing Avenue, Nanjing 216667, China \\ ${ }^{2}$ School of Transportation, Southeast University, Sipailou 2\#, Nanjing 210096, China \\ Correspondence should be addressed to Jiwang Jiang; jiang_jiwang@hotmail.com
}

Received 9 July 2020; Revised 7 September 2020; Accepted 10 September 2020; Published 13 October 2020

Academic Editor: Chiara Bedon

Copyright (c) 2020 Hongmei Li et al. This is an open access article distributed under the Creative Commons Attribution License, which permits unrestricted use, distribution, and reproduction in any medium, provided the original work is properly cited.

In order to investigate the key factors and analyze their effects on maintenance and rehabilitation (M\&R) strategies, data for 2495 pavement sections were collected from the pavement management system (PMS), including pavement performance data, traffic data, material property data, and M\&R record data. Logistic regression was first employed to explore the influential factors on maintenance probability. Afterward, the classification tree model was established to find out the key factors on resurfacing thickness. Results showed that road sections with higher IRI, rutting depth (RD), deterioration rate of surface friction coefficient (DRSFC), pavement patching ratio (PPR), and transverse cracking severity index (TCSI) before treatment had significantly higher maintenance probability, which could be quantified by the developed logistic model. Moreover, treatments implemented on bridge decks tended to have greater resurfacing thickness. For pavement M\&R projects, with the tensile strength ratio (TSR) of top layer materials higher than $88.7 \%$ and pretreatment SFC higher than 49 , the resurfacing thickness would be thinner. For bridge M\&R projects, middle layer TSR higher than $88.3 \%$ led to thinner overlays, and much thinner resurfacing thickness can be observed if pretreatment RD was less than $8.72 \mathrm{~mm}$. When middle layer TSR was lower than $88.3 \%$ and pretreatment IRI was higher than $2.383 \mathrm{~m} / \mathrm{km}$ with larger AESAL, the resurfacing thickness would probably be the thickest. The two models built in this paper provided probabilistic estimation of maintenance probability and explored key factors together with their critical split points for resurfacing thickness, which could be regarded as an alternative decision-making tool for pavement engineers.

\section{Introduction}

Pavement maintenance and rehabilitation (M\&R) planning has become one of the top priorities for transportation agencies in China. This is the case because many expressways have reached their design life (20 years in average) or more. There are several M\&R treatments at the disposal of transportation agencies; however, selecting an effective treatment and determining the optimum time to apply this treatment is necessary to fulfill the overall goal of M\&R planning and the pavement management system (PMS) [1-3].

Pavement deterioration is recognized to be uncertain due to the inherent variability in the material properties and the big challenge of collecting good quality data for performance modeling. To account for this uncertainty, researchers have developed various probabilistic models to simulate the deterioration process and forecast future conditions [4-7]. The uncertainty of pavement deterioration also leads to the variability in both M\&R effectiveness and timing. However, so far, the most widely used decisionmaking method in practical pavement $M \& R$ projects is still "worst-first." In other words, M\&R activities are always implemented when the performance indicators (such as RD, IRI, and PSI) meet the predefined threshold or trigger value, which indicates that a pavement is in a bad condition $[8,9]$. As a typical example of the "worst-first" approaches, hierarchical decision tree was frequently established because of their simple structure and easy to implement feature [10-15]. Generally, hierarchical decision tree is defined by a series of "if this occurs then this occurs" conditions that lead to a specific decision. These conditions and the resulting 
decisions are often determined by experienced pavement experts and hence tend to be deterministic. It means, when the threshold is reached, only two mutually exclusive options could be chosen: conducting the corresponding treatment at the end node of the decision tree or do nothing. Nevertheless, engineers are now seeking for more flexible ways to conduct the pavement $M \& R$ planning rather than a yes or no answer.

Pavement M\&R records are valuable databases, which contain underlying decision logic from many experienced pavement experts. Previous research has proposed various methods to make the decision-making procedure more straightforward and easier to conduct [14]. However, probabilistic decisions, which could provide more useful information to decision-makers, are rarely seen. In this paper, the maintenance probability index was proposed, which is defined as the probability that an M\&R treatment is required under specific conditions. Actually, quantifying the maintenance probability instead of acquiring a deterministic decision would be more advantageous to adjust the M\&R strategy and budget allocation when some compromises had to be made in network level optimization because the maintenance probability also indicates the urgency of each $\mathrm{M} \& \mathrm{R}$ project.

After estimating the maintenance probability, the remaining challenge is to determine the specific $M \& R$ treatment. Several alternative treatments with different intensities are available, including slurry seal, microsurfacing, hot-in-place recycling, milling and resurfacing, and so force. Among them, milling and resurfacing different depths of the pavement surface layer is one of the most commonly used M\&R treatments in Jiangsu province. In addition, choosing between milling and resurfacing and other treatments is much simpler than determining the appropriate depth of milling and resurfacing. Thus, this paper mainly focusses on the latter. Research studies have demonstrated that thicker overlay lead to lower roughness after rehabilitation and delayed the propagation of reflective cracking significantly but increased the rutting depth sometimes [16-18]. However, engineers often get stuck in choosing an appropriate milling and resurfacing thickness if field core tests were not performed. Therefore, it is crucial to explore and summarize the controlling factors of resurfacing thickness from the M\&R history.

From the literature review, it could be concluded that there are still several research gaps in the existing literatures: (1) very few studies consider the uncertainty of decisionmaking in pavement management. Even the most state-ofart methods tend to generate deterministic optimization results only [19]; (2) while most studies are now engaged into finding the optimal M\&R strategies with the help of sophisticated mathematical algorithms, they are actually based on simplified performance models and many assumptions. In contrast, the real decision logic in the PMS, based on a wealth of valuable expertise, has not been fully utilized; (3) when selecting the specific resurfacing thickness in practical M\&R projects, engineers either conduct field core tests or rely on those predefined decision trees, with the former being destructive and the latter only including pavement performance indicators in most cases. Although lots of optimization algorithms have been applied in this area, many assumptions need to be made to make sure that the problem is solvable [20].

In response to the above research gaps, this study aims to (a) quantify the maintenance probability under different conditions and explore the influential factors on maintenance probability by logistic regression and (b) investigate the key factors on resurfacing thickness through the classification tree model. The pavement performance data were collected from the pavement management system (PMS) in Jiangsu. A total of 2495 pavement sections with or without $M \& R$ activities were investigated. Differing from the previous studies, which employed the pavement performance indicators defined in the Chinese national standards to build the models, the specific types of pavement distresses were considered in this research. For instance, transverse crack and patching were separated out from pavement surface condition index (PCI). Additionally, the detailed material properties of each pavement structure were considered. In view of the data availability and reliability, only the indicators of dynamic stability (DS), retained Marshall stability $\left(\mathrm{MS}_{0}\right)$, tensile strength ratio (TSR), and failure strain $\left(-10^{\circ} \mathrm{C}\right)$ from the three-point beam bending test were utilized. The models built in this study integrate a great deal of pavement engineering expertise while making the decision-making process more flexible and direct. Compared with the existing pavement maintenance decision-making methods employed in practical $\mathrm{M} \& \mathrm{R}$ projects (such as those based on hierarchical decision tree, ranking method, or individual expert opinion), the developed logistic model produces probabilistic estimation of maintenance timing and is hence thought to be more flexible. Instead of using performance thresholds, decision-makers could also set threshold on maintenance probability. This allows them to easily adjust the maintenance probability that triggers $M \& R$ activity based on the available budget. Moreover, with the classification tree model, a preliminary estimate of resurfacing thickness could be made.

\section{Data Processing}

The data used in this research were collected from a two-way six-lane expressway in Jiangsu named "Yanhai Expressway," which has been opened to traffic for more than 13 years. The overall length of this expressway is about $318 \mathrm{~km}$ with eight different pavement structures, as shown in Table 1. SMA denotes a stone mastic asphalt mixture, while $\mathrm{AK}, \mathrm{AC}$, and SUP denote the asphalt mixtures with different densegraded gradations, and OGFC denotes one open-graded friction course. 13, 20, and 25 denote the maximum nominal aggregate sizes (NMAS) in millimeters. $M$ in Table 1 denotes a modified asphalt binder meeting the Superpave grading of PG76-22, while $N$ denotes a neat asphalt binder with a grade of $60 / 70$. The detailed gradation or volumetric properties of the asphalt mixtures could be found in the Chinese specification of JTG D50-2017. There is no significant difference in climatic conditions in the area where the entire highway is located. Thus, the climate impact is not considered in this 
TABle 1: Pavement structures of Yanhai expressway.

\begin{tabular}{lccc}
\hline Structure number & Top layer material & Middle layer material & Bottom layer material \\
\hline 1 & M.SMA-13 & M.SUP-20 & SUP-25 \\
2 & M.SMA-13 & M.AC-20 & AC-25 \\
3 & M.AK-13 & M.AC-20 & AC-25 \\
4 & M.SMA-13 & M.AC-20 & M.AC-25 \\
5 & M.SMA-13 & M.SUP-20 & AC-25 \\
6 & M.AK-13 & M.AC-20 & M.AC-25 \\
7 & M.AK-13 & M.SUP-20 & SUP-25 \\
8 & M.OGFC-13 & M.SUP-20 & SUP-25 \\
\hline
\end{tabular}

Note. M.SMA-13 denotes a stone mastic asphalt mixture with NMAS of $13 \mathrm{~mm}$ fabricated by a PG76-22 modified asphalt binder.

paper. Many M\&R treatments have been carried out on each individual lane to repair specific pavement distresses. Due to the lack of data of the first lane located beside the central divider (the passing lane), only M\&R treatments applied on the second and third lanes (the driving lanes) were analyzed in this research.

2.1. Road Section Segmentation. As mentioned before, Yanhai expressway contains eight different structures, and the materials of each structure differs from each other. Overlapping maintained sections could be observed due to the repetitive use of M\&R treatments on the deteriorated pavements during the past 13 years. Therefore, in order to analyze the impact of a single factor, it is necessary to divide the whole expressway into shorter sections according to the M\&R records and pavement structures. As a result, road sections with different milestones, directions, lanes, or M\&R times were treated as separate projects. Finally, a total of 2495 projects including 1793 road sections were obtained, and this data would be used to build the models in this study.

Figure 1 shows the count and overall length of sections with one or more treatments or without treatments (routine maintenance was not included). The statistical results of different lanes can be distinguished by the different shades of red. It can be found that about $96.23 \%$ of the road sections has not been maintained yet, which means the relatively better condition of Yanhai expressway. Among the maintained sections, being maintained for once shows the maximum proportion. Moreover, no obvious difference is observed among different lanes.

2.2. Data Integration. After the segmentation of road sections, traffic loads, pavement material indicators, M\&R information (if available), and pretreatment performance indicators were matched with each section.

Annual $100 \mathrm{kN}$ equivalent single-axle load (AESAL) was selected as an indicator of traffic level, with a mean of $42.16 \times$ $10^{4}$ and a standard deviation of $29.89 \times 10^{4}$ in the case of Yanhai expressway. Table 2 presents the material indicators, which reflect the high-temperature performance, moisture stability, and low-temperature crack resistance of asphalt mixtures of each surface layer. Some information are limited because of the difficulty of integrating older construction documents into the database.
Of all the M\&R projects, nearly $99 \%$ was milling and resurfacing. Therefore, M\&R information consists of milling depth, resurfacing thickness, resurfacing material, and M\&R application time. Figure 2 shows the statistical distributions of these four variables, with the vertical axis denoting the value of the variable, and the height is the count of the M\&R projects. The diamond and the horizontal line within the box plot represent the mean and median value, respectively. The top and bottom edge of the box denote the upper and lower quartiles, and the points are the outliers. It can be seen that milling depths are approximately equal to resurfacing thicknesses, implying that thickness-added major rehabilitation is not included in this study. Two peaks can be observed with one between 4 and 5 centimeters and the other between 10 and 11 centimeters. Figure 2(c) indicates that nearly half of the M\&R projects milled the top layer and resurfaced AC-13, which is a dense-graded asphalt concrete with a maximum nominal aggregate size (NMAS) of 13 millimeters. AC-13 was frequently used as a top resurfacing layer, and its mix design was determined based on the Chinese specification of JTG D50-2017. Regarding the $M \& R$ application time, there are also two peaks: one appears in the 4th year and the other appears in the 8th year, suggesting that extensive $M \& R$ activities emerged on Yanhai expressway periodically with an average period of 4 years.

Pretreatment performance is an important factor influencing the selection of M\&R strategy. Because of the available data in PMS, it is possible to obtain the required pretreatment performance data to carry on the research. Instead of using the performance indicators defined in Chinese national standards, the original detection data were employed by taking the specific types of pavement distresses into consideration. Zhou et al. [21] separated out transverse cracking and patching from PCI for the reason that reflection crack is one of the main distresses of asphalt pavement in China, and patching reflects the history of pavement distress. Transverse cracking condition index (TCCI) has been defined as the ratio of average transverse crack spacing and transverse crack width ratio (TCS and TWR) to describe the severity of transverse cracks on the investigated sections with a lower value representing more severe condition. In this paper, the transverse cracking severity index (TCSI), which is the reciprocal of TCCI, was proposed to ensure that TCSI is a numerical value even if 


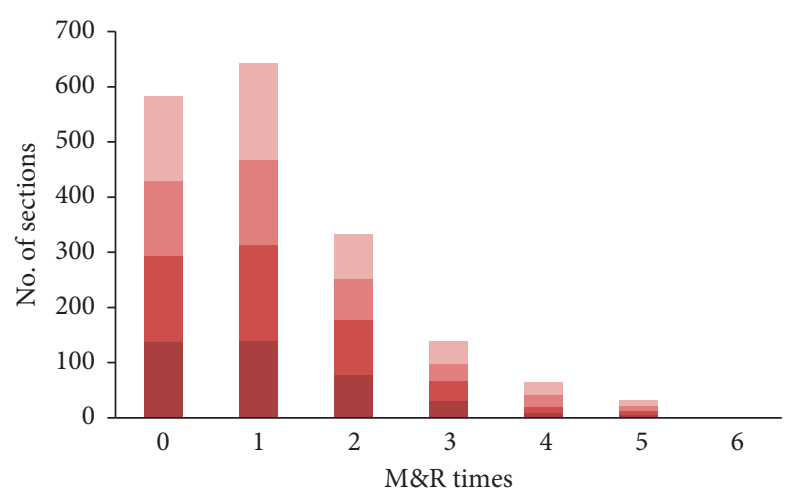

- Direct. 1 lane 2

- Direct. 1 lane 3

$$
\begin{aligned}
& \text { Direct. } 2 \text { lane } 2 \\
& \text { Direct. } 2 \text { lane } 3
\end{aligned}
$$

(a)

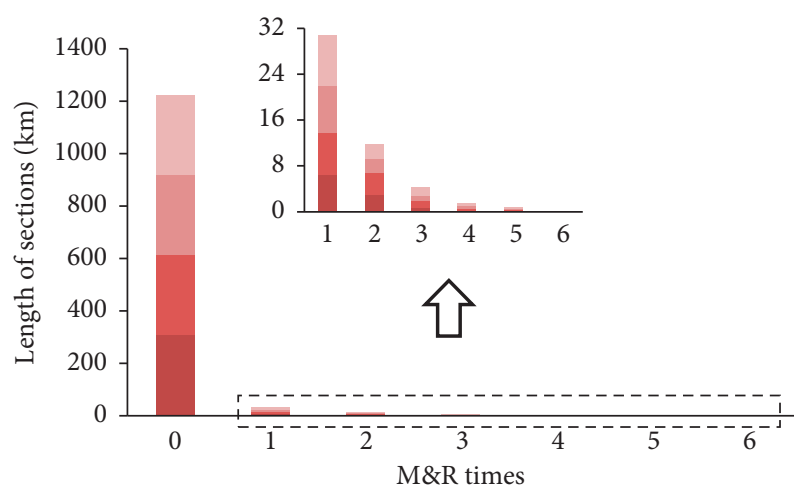

- Direct. 1 lane 2

- Direct. 1 lane 3
- Direct. 2 lane 2

- Direct. 2 lane 3

(b)

Figure 1: The amount and overall length of sections with or without M\&R. (a) Counts. (b) Length.

TABLE 2: The utilized material indicators.

\begin{tabular}{lcc}
\hline Top layer & Middle layer & Bottom layer \\
\hline Dynamic stability (DS) & Dynamic stability (DS) & NA \\
Retained Marshall stability $\left(\mathrm{MS}_{0}\right)$ & Retained Marshall stability $\left(\mathrm{MS}_{0}\right)$ & NA \\
Tensile strength ratio (TSR) & Tensile strength ratio (TSR) & NA \\
Failure strain $\left(-10^{\circ} \mathrm{C}\right)$ & Failure strain $\left(-10^{\circ} \mathrm{C}\right)$ & Failure strain $\left(-10^{\circ} \mathrm{C}\right)$ \\
\hline
\end{tabular}

Note. NA represents no data.

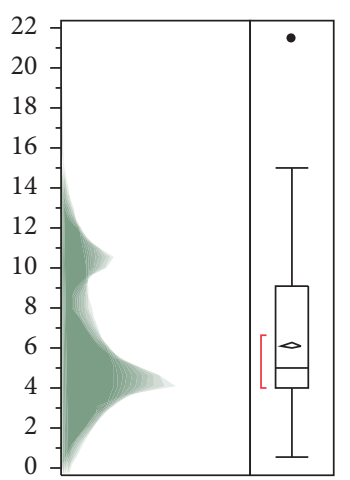

(a)

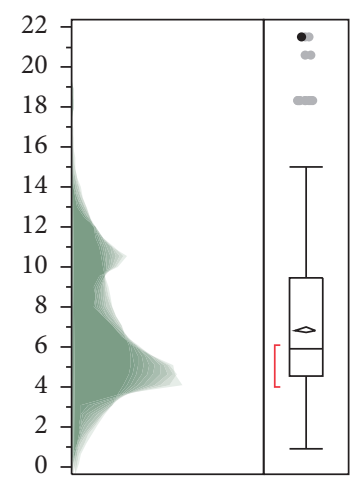

(b)

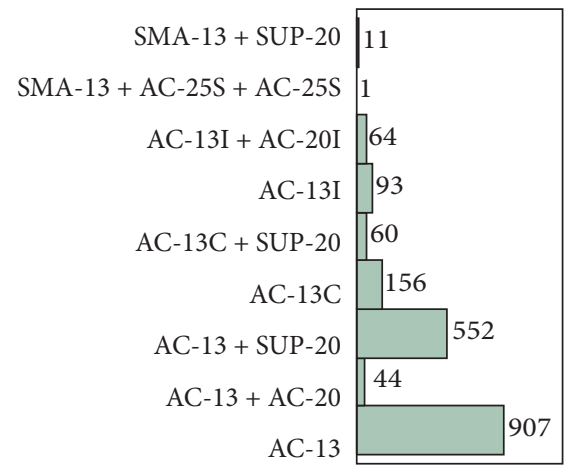

(c)

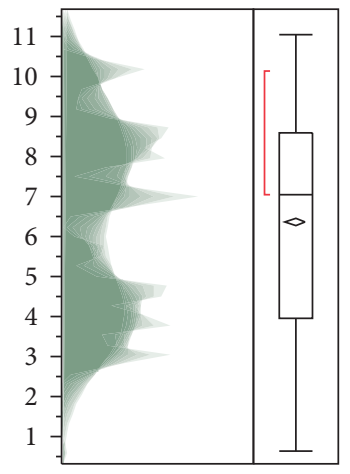

(d)

Figure 2: The distribution diagrams of M\&R information of all the M\&R projects. (a) Milling depth (cm). (b) Resurfacing thickness (cm). (c) Resurfacing material. (d) M\&R application time (year).

there is no transverse crack. Equations (1) (6) show the specific calculation formulas of TCSI and pavement patching ratio $(\mathrm{PPR})$ :

$$
\begin{aligned}
\text { TCS } & =\frac{L}{\mathrm{TCN}}, \\
\mathrm{TCL} & =\frac{\mathrm{TCTL}}{\mathrm{TCN}}, \\
\mathrm{TWR} & =\frac{\mathrm{TCL}}{B},
\end{aligned}
$$

$$
\begin{aligned}
& \text { TCCI }=\frac{T C S}{T W R}, \\
& \text { TCSI }=\frac{1}{\text { TCCI }},
\end{aligned}
$$

where TCCI is the transverse crack condition index (dimensionless), TCS is the average transverse crack spacing (m), TWR is the transverse crack width ratio (dimensionless) (if TWR value is higher than 1.0, TWR is set to be 1.0), TCL is the transverse crack average length $(\mathrm{m}), \mathrm{TCN}$ is the number of transverse cracks, TCTL is the transverse crack 
total length (m), $L$ is the length of pavement section (m), and $B$ is the width of pavement section $(\mathrm{m})$ :

$$
\mathrm{PPR}=100 \times \frac{\sum_{i=1}^{n} A_{i}}{A},
$$

where PPR is the pavement patching ratio (\%), $A_{i}$ is the the area of the $i^{\text {th }}$ patching $\left(\mathrm{m}^{2}\right)$, and $A$ is the the area of the pavement section $\left(\mathrm{m}^{2}\right)$.

In addition, linear models were established for each project because no obvious curvature could be observed between pavement age and pretreatment performance indicators. Thus, the deterioration rates of IRI, RD, and SFC before M\&R treatment could be obtained from the slopes of linear models. Due to the large amount of zero values in TCSI, PPR, and SDR, the deterioration rates of them can hardly be calculated. Consequently, the performance indicators are summarized in Table 3.

\section{Methodology of Statistical Analysis}

Two statistical analysis methods including logistic regression and classification tree were utilized to study the influence of different factors on maintenance probability and resurfacing thickness, respectively.

3.1. Logistic Regression. Logistic regression is an appropriate method to model a binary dependent variable as a function of predictors. It has been applied to model a wide variety of transportation and pavement related data, including traffic accidents, pavement fatigue cracking, pavement patching effect, and selection of preservation projects [22-26]. In this research, the goal of logistic regression is to describe how the predictors influence the probability that $M \& R$ will be required. Equation (7) shows the logistic regression equation. The logit function of $\mathrm{P}$, defined as the natural logarithm transformation of the odds ratio, is expressed as a linear combination of predictors:

$$
\begin{aligned}
Y= & \operatorname{logit}(P)=\ln \left(\frac{P}{1-P}\right)=\beta_{0}+\beta_{1} X_{1}+\beta_{2} X_{2}+\cdots \\
& +\beta_{i} X_{i}+\cdots+\beta_{n} X_{n}
\end{aligned}
$$

where $P$ is the maintenance probability; $X_{i}$ is the predictors (including AESAL, Pre-IRI, Pre-RD, Pre-TCSI, Pre-PPR, and Pre-DR $\left.\mathrm{DFC}_{\mathrm{SFC}}\right) ; \beta_{i}$ is the parameter estimate of predictor $X_{i}$, which is the magnitude and direction change in response with each one-unit increase in predictor $X_{i}$; and $\beta_{0}$ is a model constant.

3.2. Classification Tree. The classification tree is an effective data mining method to statistically classify data into subsets with similar attributes. A trained classification tree can be used to predict target values based on the attributes of a data sample. This method has been widely used in many areas such as credit scoring, bank bankruptcy prediction, signal recognition, medical diagnosis, and so on. In transportation engineering, the classification tree has been used to investigate the influence of different factors on traffic accidents by many researchers [27-29]. Pavement engineers also utilized the classification tree to predict the probability of maintenance and to select particular M\&R activities based on the current pavement condition [30].

In this research, classification and regression tree (CART), which contains two branches for each decision node, was utilized to classify the resurfacing thicknesses of each M\&R project into different groups based on their attributes including directions, lanes, traffic levels, material indicators, pretreatment performance, characteristics of road sections (pavement or bridge), and M\&R times.

\section{Discussion of Results}

4.1. Logistic Regression. Figure 3 and Table 4 display the results of logistic regression and the significance test of each predictor, respectively. As shown in Figure 3, the number next to " 1 " in the left part of the figure denotes the probability that M\&R is needed, while the number next to " 0 " denotes the probability that M\&R is needless. Consequently, the black line shows how the probability changes corresponding to the change of each predictor. In addition, factors with $P$ values lower than 0.05 in Table 4 are considered as significant factors.

It can be found that Pre-IRI, Pre-RD, and Pre-DR $\mathrm{SFC}_{\mathrm{S}}$ are significant factors for the maintenance probability. Higher IRI, deeper rutting, and faster deterioration of skid-resistance before treatment clearly increase the maintenance probability. Moreover, more severe transverse cracking and higher patching ratio improve the probability of maintenance as well. While AESAL seems to have little influence on maintenance probability, it can still be observed that high AESAL slightly increased the probability. The insignificant impact of AESAL may be due to the similar traffic levels on the investigated road sections. Therefore, it can be concluded that traffic is not the main cause of the different maintenance probabilities of a road sections in the same expressway. Instead, it is the pavement condition that directly decides the maintenance probability. Furthermore, given this logistic regression model, decision-makers can easily obtain the maintenance probability as long as the pavement performance data have been collected. Therefore, calculating the maintenance probability could be considered as an alternative approach to determine the M\&R timing in addition to the frequently used threshold-based M\&R decision-making method.

Furthermore, the influence of pavement structure composition was not considered in the logistic model since the high variability of the material property indicators may have negative effects on regression. However, it should have some implications when involved in classification problems, which is covered in the following section of the paper.

4.2. Classification Tree. The unmaintained projects and those with insufficient material data were eliminated. Consequently, a total of $355 \mathrm{M} \& \mathrm{R}$ projects were used to 
TABLE 3: The performance indicators.

\begin{tabular}{|c|c|c|}
\hline Indicators & Full name & Description \\
\hline Pre-IRI $(\mathrm{m} / \mathrm{km})$ & $\begin{array}{l}\text { Pretreatment international } \\
\text { roughness index }\end{array}$ & IRI value in the last detection before treatment \\
\hline Pre-RD (mm) & Pretreatment rutting depth & $\mathrm{RD}$ value in the last detection before treatment \\
\hline Pre-SFC & $\begin{array}{l}\text { Pretreatment side-way force } \\
\text { coefficient }\end{array}$ & SFC value in the last detection before treatment \\
\hline Pre-TCSI $(\% / \mathrm{m})$ & $\begin{array}{l}\text { Pretreatment transverse cracking } \\
\text { severity index }\end{array}$ & TCSI value in the last detection before treatment \\
\hline Pre-PPR (\%) & $\begin{array}{l}\text { Pretreatment pavement patching } \\
\text { ratio }\end{array}$ & $\begin{array}{c}\text { The patching ratio (including patching and surface pit) in the last detection } \\
\text { before treatment }\end{array}$ \\
\hline Pre-SDR (\%) & Pretreatment surface damage ratio & $\begin{array}{c}\text { The surface damage ratio (except for transverse crack, patching, and surface pit) } \\
\text { in the last detection before treatment }\end{array}$ \\
\hline $\begin{array}{l}\text { Pre-DR } \mathrm{DRI}_{\mathrm{IRI}}(\mathrm{m} / \mathrm{km} / \\
\text { year) }\end{array}$ & $\begin{array}{l}\text { Pretreatment deterioration rate of } \\
\text { IRI }\end{array}$ & The slope of the pretreatment IRI linear deterioration model \\
\hline $\begin{array}{l}\text { Pre-DR } \mathrm{RD}_{\mathrm{RD}}(\mathrm{mm} / \\
\text { year })\end{array}$ & $\begin{array}{l}\text { Pretreatment deterioration rate of } \\
\text { RD }\end{array}$ & The slope of the pretreatment RD linear deterioration model \\
\hline Pre-DR $\mathrm{SFC}_{\mathrm{S}}$ & $\begin{array}{l}\text { Pretreatment deterioration rate of } \\
\text { SFC }\end{array}$ & The slope of the pretreatment SFC linear deterioration model \\
\hline
\end{tabular}

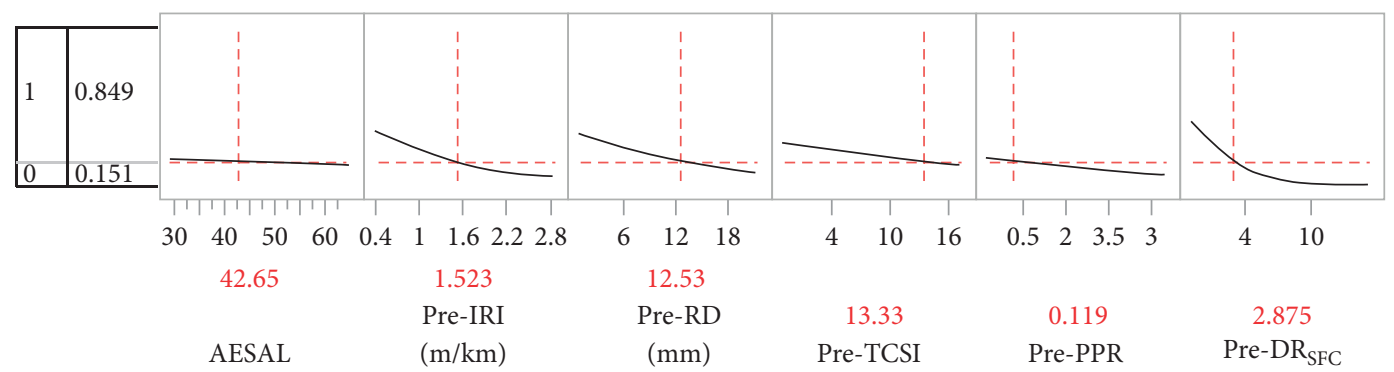

Figure 3: Prediction profiler.

TABLE 4: Effect likelihood ratio test.

\begin{tabular}{lccc}
\hline Term & $\mathrm{d} f$ & L-R chi-square & $P$ value \\
\hline AESAL & 1 & 0.57653427 & 0.4477 \\
Pre-IRI $(\mathrm{m} / \mathrm{km})$ & 1 & 37.2497417 & $<0.0001^{*}$ \\
Pre-RD $(\mathrm{mm})$ & 1 & 4.3116232 & $0.0379^{*}$ \\
TCSI & 1 & 0.96879206 & 0.3250 \\
Pre-PPR & 1 & 1.75930143 & 0.1847 \\
Pre-DR & 1 & 73.4634142 & $<0.0001^{*}$ \\
\hline
\end{tabular}

*Statistically significant.

conduct the CART analysis. Figure 4 shows the developed CART tree by using resurfacing thickness as the classification target. For the $355 \mathrm{M} \& \mathrm{R}$ projects, the first split variable is whether the corresponding section is pavement or bridge. The M\&R treatments implemented on bridge deck tended to have a greater resurfacing thickness, with an average thickness of 9 centimeters while that for pavement was 6.5 centimeters.

The 242 pavement M\&R projects were then split into two subsets according to top layer TSR. The road sections with top layer TSR higher than $88.7 \%$ required thinner overlays, with an average of 7 centimeters while that for TSR lower than $88.7 \%$ was 5.5 centimeters. Then, the pretreatment SFC was selected as a significant attribute to split, indicating that lower pretreatment SFC would result in thicker overlays.
For the 104 bridge M\&R projects, middle layer TSR was selected as a significant attribute first. Middle layer TSR higher than $88.3 \%$ led to thinner overlays, and much thinner resurfacing thickness can be observed if pretreatment $\mathrm{RD}$ was less than $8.72 \mathrm{~mm}$. At the other branch with middle layer TSR lower than $88.3 \%$, it can be found that larger AESAL caused thicker overlays. When the pretreatment IRI value is higher than $2.383 \mathrm{~m} / \mathrm{km}$, the resurfacing thickness would probably be the thickest.

The special geographic location of Yanhai expressway leads to abundant rainfall along the line. Therefore, the water stability of asphalt mixture of pavement surface layer plays an important role in pavement surface condition and the selection of M\&R treatment, which can be concluded from the classification tree's results. Top layer TSR is the first split variable for thinner overlays, while middle layer TSR is for thicker overlays. Although TSR seems like an indirect factor in the selection of resurfacing thickness, it exactly has a great influence on pavement conditions, which directly affects the M\&R planning later. It is worth noting that for other regions with significantly different weather condition compared with this case, the TSR may not play such an important role in pavement maintenance decisions, but some other material properties shall stand out and have a more dominate effect.

Moreover, the pretreatment performance, including SFC, RD, and IRI, and traffic level, also have great impacts on 


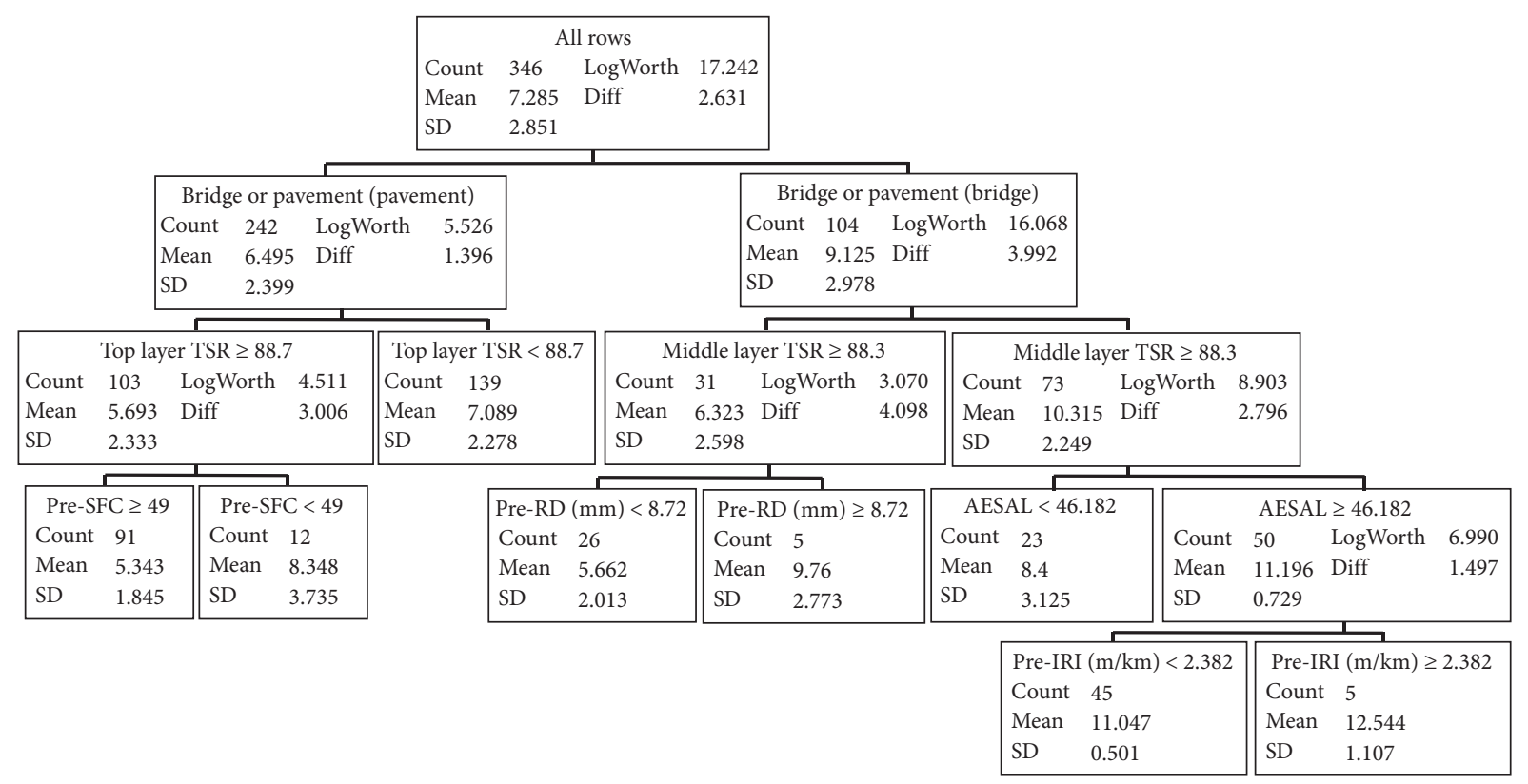

(a)

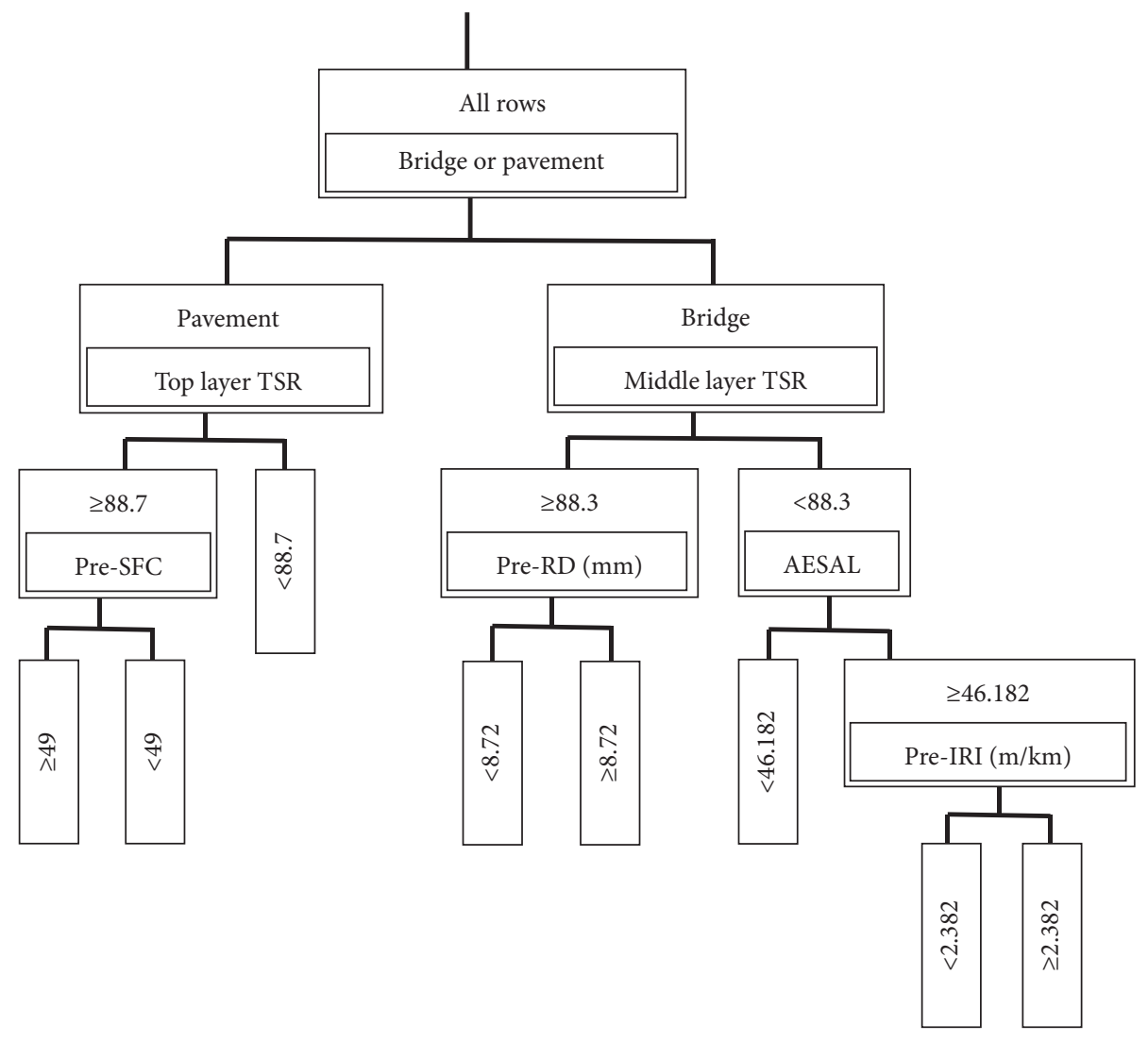

(b)

FIGURE 4: Results of classification tree analysis of resurfacing thickness: (a) Specific version. (b) Simplified version. 
resurfacing thickness. The SFC of 49 , a rutting depth of $8.72 \mathrm{~mm}$, and an IRI of $2.382 \mathrm{~m} / \mathrm{km}$ appear to be key values when determining the degree of milling and resurfacing. As a result, agencies can refer to this classification tree for a preliminary resurfacing thickness selection, which would bring great convenience to them.

\section{Conclusion}

This paper quantified the maintenance probability under specific pavement conditions and investigated the key factors on resurfacing thickness. The data of Yanhai expressway collected from PMS were utilized to conduct the analysis. Based on the results, the following conclusions could be drawn:

(1) The developed logistic model was capable to provide probabilistic estimation for maintenance probability given the pretreatment performance and traffic loads. The classification tree model further shows the key factors and their critical split point for determining the resurfacing thickness.

(2) Higher IRI, deeper rutting, and faster deterioration of skid-resistance before treatment significantly increase the maintenance probability. More severe transverse cracking and higher patching ratio also improve the probability of maintenance. AESAL slightly increased the probability of maintenance.

(3) The key factors on resurfacing thickness include the characteristic of road sections (pavement or bridge), top layer and middle layer TSR, pretreatment SFC, RD, and IRI, and AESAL. The $M \& R$ treatments implemented on bridge tended to have obviously greater resurfacing thickness.

(4) For pavement M\&R projects, the road sections with top layer TSR higher than $88.7 \%$ required thinner overlays. In addition, with pretreatment SFC higher than 49 , the desired resurfacing thickness would be smaller.

(5) For bridge M\&R projects, middle layer TSR higher than $88.3 \%$ led to thinner overlays, and much thinner resurfacing thickness can be observed if pretreatment RD was less than 8.72 millimeter. With middle layer TSR lower than $88.3 \%$, larger AESAL, and pretreatment IRI higher than $2.383 \mathrm{~m} / \mathrm{km}$, the required resurfacing thickness would probably be the thickest.

However, it is also worth noting that decision-making in pavement management is a complex expertise. The models and methods in this study were developed from a practical point of view. Although they are easy to use in practice, improved approaches and various factors are desired in following research. For instance, climate conditions should be considered as candidate factors. Larger dataset collected from multiple expressways with different traffic level and pavement performance is required as well.

\section{Data Availability}

The PMS data used to support the findings of this study are available from the corresponding author upon request.

\section{Conflicts of Interest}

The authors declare that they have no conflicts of interest.

\section{Acknowledgments}

The authors are grateful for the financial support from the Scientific Research Foundation of Nanjing Institute of Technology (YKJ201728).

\section{References}

[1] A. V. Moreira, J. Tinoco, J. R. M. Oliveira, and A. Santos, “An application of Markov chains to predict the evolution of performance indicators based on pavement historical data," International Journal of Pavement Engineering, vol. 19, no. 10, pp. 937-948, 2018.

[2] A. G. Matin, R. V. Nezafat, and A. Golroo, "A comparative study on using meta-heuristic algorithms for road maintenance planning: insights from field study in a developing country," Journal of Traffic and Transportation Engineering (English Edition), vol. 4, no. 5, pp. 477-486, 2017.

[3] A. Pantuso, G. Loprencipe, G. Bonin, and B. B. Teltayev, "Analysis of pavement condition survey data for effective implementation of a network level pavement management program for Kazakhstan," Sustainability, vol. 11, no. 3, p. 901, 2019.

[4] H. Pérez-Acebo, S. Bejan, and H. Gonzalo-Orden, “Transition probability matrices for flexible pavement deterioration models with half-year cycle time," International Journal of Civil Engineering, vol. 16, no. 9, pp. 1045-1056, 2018.

[5] A. Pantuso, G. W. Flintsch, S. W. Katicha, and G. Loprencipe, "Development of network-level pavement deterioration curves using the linear empirical Bayes approach," International Journal of Pavement Engineering, pp. 1-14, 2019.

[6] R. Hassan, O. Lin, and A. Thananjeyan, "A comparison between three approaches for modelling deterioration of five pavement surfaces," International Journal of Pavement Engineering, vol. 18, no. 1, pp. 26-35, 2017.

[7] J. Jiang, F. Ni, Q. Dong, Y. Zhao, and K. Xu, "Fatigue damage model of stone matrix asphalt with polymer modified binder based on tensile strain evolution and residual strength degradation using digital image correlation methods," Measurement, vol. 123, pp. 30-38, 2018.

[8] P. C. Anastasopoulos, M. T. Sarwar, and V. N. Shankar, "Safety-oriented pavement performance thresholds: accounting for unobserved heterogeneity in a multi-objective optimization and goal programming approach," Analytic Methods in Accident Research, vol. 12, pp. 35-47, 2016.

[9] M. M. Hasan, A. S. M. A. Rahman, and R. A. Tarefder, "Investigation of accuracy of pavement mechanistic empirical prediction performance by incorporating level 1 inputs," Journal of Traffic and Transportation Engineering (English Edition), vol. 7, no. 2, pp. 259-268, 2020.

[10] S. Chi, J. Hwang, M. Arellano, Z. Zhang, and M. Murphy, "Development of network-level project screening methods supporting the 4-year pavement management plan in Texas," Journal of Management in Engineering, vol. 29, no. 4, pp. 482-494, 2013. 
[11] M. G. Augeri, S. Greco, and V. Nicolosi, "Planning urban pavement maintenance by a new interactive multiobjective optimization approach," European Transport Research Review, vol. 11, no. 1, p. 17, 2019.

[12] Q. Dong, C. Dong, and B. Huang, "Statistical analyses of field serviceability of throw-and-roll pothole patches," Journal of Transportation Engineering, vol. 141, no. 9, Article ID 04015017, 2015.

[13] X. Jia, B. Huang, Q. Dong, D. Zhu, and J. Maxwell, "Influence of pavement condition data variability on network-level maintenance decision," Transportation Research Record: Journal of the Transportation Research Board, vol. 2589, no. 1, pp. 20-31, 2016.

[14] O. Elbagalati, M. A. Elseifi, K. Gaspard, and Z. Zhang, "Development of an enhanced decision-making tool for pavement management using a neural network pattern-recognition algorithm," Journal of Transportation Engineering, Part B: Pavements, vol. 144, no. 2, Article ID 04018018, 2018.

[15] M. Hafez, K. Ksaibati, and R. Atadero, "Integration of optimization methodology to evaluate pavement maintenance strategies for deteriorated low-volume roads," Canadian Journal of Civil Engineering, vol. 46, no. 2, pp. 104-113, 2019.

[16] C. Chen, R. Christopher Williams, M. G. Marasinghe et al., "Assessment of composite pavement performance by survival analysis," Journal of Transportation Engineering, vol. 141, no. 9, Article ID 04015018, 2015.

[17] S. S. Hung, A. Rezaei, and J. T. Harvey, "Effects of milling and other repairs on smoothness of overlays on asphalt pavements," Transportation Research Record: Journal of the Transportation Research Board, vol. 2408, no. 1, pp. 86-94, 2014.

[18] W. Zhang, S. Shen, S. Wu, and L. N. Mohammad, "Prediction model for field rut depth of asphalt pavement based on Hamburg wheel tracking test properties," Journal of Materials in Civil Engineering, vol. 29, no. 9, Article ID 04017098, 2017.

[19] L. Yao, Q. Dong, J. Jiang, and F. Ni, "Deep reinforcement learning for long-term pavement maintenance planning," Computer-Aided Civil and Infrastructure Engineering, 2020.

[20] Y. Li and S. Madanat, "A steady-state solution for the optimal pavement resurfacing problem," Transportation Research Part A: Policy and Practice, vol. 36, no. 6, pp. 525-535, 2002.

[21] L. Zhou, F. Ni, and Y. Zhao, "Evaluation method for transverse cracking in asphalt pavements on freeways," Transportation Research Record: Journal of the Transportation Research Board, vol. 2153, no. 1, pp. 97-105, 2010.

[22] J. Liu, J. Li, K. Wang, J. Zhao, H. Cong, and P. He, "Exploring factors affecting the severity of night-time vehicle accidents under low illumination conditions," Advances in Mechanical Engineering, vol. 11, no. 4, 2019.

[23] B. R. Yang, K.-e. Kwon, Y.-J. Kim et al., "The association between antidepressant use and deaths from road traffic accidents: a case-crossover study," Social Psychiatry and Psychiatric Epidemiology, vol. 54, no. 4, pp. 485-495, 2019.

[24] S. W. Haider and K. Chatti, "Effect of design and site factors on fatigue cracking of new flexible pavements in the LTPP SPS-1 experiment," International Journal of Pavement Engineering, vol. 10, no. 2, pp. 133-147, 2009.

[25] D. Chen, T. Cavalline, and N. Mastin, "Development of piecewise linear performance models for flexible pavements using PMS data," Journal of Performance of Constructed Facilities, vol. 29, no. 6, Article ID 04014148, 2015.

[26] D. Kim, S. Chi, and J. Kim, "Selecting network-level project sections for sustainable pavement management in Texas," Sustainability, vol. 10, no. 3, p. 686, 2018.
[27] V. Rovšek, M. Batista, and B. Bogunović, "Identifying the key risk factors of traffic accident injury severity on Slovenian roads using a non-parametric classification tree," Transport, vol. 32, no. 3, pp. 272-281, 2017.

[28] T. B. Tesema, A. Abraham, and C. Grosan, "Rule mining and classification of road traffic accidents using adaptive regression trees," International Journal of Simulation, vol. 6, no. 10, pp. 80-94, 2005.

[29] X. Yan and E. Radwan, "Analyses of rear-end crashes based on classification tree models," Traffic Injury Prevention, vol. 7, no. 3, pp. 276-282, 2006.

[30] M. Kang, M. Kim, and J. H. Lee, "Analysis of rigid pavement distresses on interstate highway using decision tree algorithms," KSCE Journal of Civil Engineering, vol. 14, no. 2, pp. 123-130, 2010. 